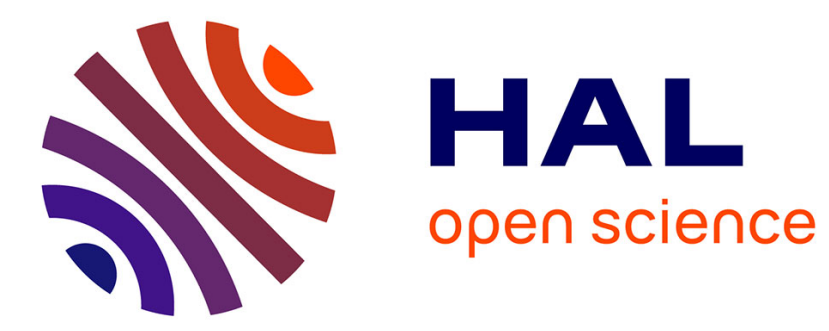

\title{
Origin of the $111\langle 112\rangle$ Cold Rolling Texture Development in a Soft Magnetic Fe-27\%Co Alloy
}

Brahim Nabi, Anne-Laure Helbert, Hiba Azzeddine, Djamel Bradai, Francois

Brisset, Thierry Waeckerle, Véronique Aubin, Thierry Baudin

\section{- To cite this version:}

Brahim Nabi, Anne-Laure Helbert, Hiba Azzeddine, Djamel Bradai, Francois Brisset, et al.. Origin of the 111 $\langle 112\rangle$ Cold Rolling Texture Development in a Soft Magnetic Fe-27\%Co Alloy. Journal of Materials Engineering and Performance, 2019, 28 (6), pp.3767-3776. 10.1007/s11665-019-04126-8 . hal-02360008

\section{HAL Id: hal-02360008 https://hal.science/hal-02360008}

Submitted on 6 Dec 2019

HAL is a multi-disciplinary open access archive for the deposit and dissemination of scientific research documents, whether they are published or not. The documents may come from teaching and research institutions in France or abroad, or from public or private research centers.
L'archive ouverte pluridisciplinaire HAL, est destinée au dépôt et à la diffusion de documents scientifiques de niveau recherche, publiés ou non, émanant des établissements d'enseignement et de recherche français ou étrangers, des laboratoires publics ou privés. 


\title{
Origin of the $\{111\}<112>$ cold rolling texture development in a soft magnetic Fe- $27 \%$ Co alloy
}

\author{
Brahim Nabi ${ }^{1}$, Anne-Laure Helbert ${ }^{1}$, Hiba Azzeddine ${ }^{2}$, Djamel Bradai ${ }^{2}$, François Brisset ${ }^{1}$, Thierry \\ Waeckerlé ${ }^{3}$, Véronique Aubin ${ }^{4}$ and Thierry Baudin ${ }^{1}$ \\ ${ }^{1}$ ICMMO, Univ. Paris-Sud, Université Paris-Saclay, UMR CNRS 8182, bât. 410, 91405 Orsay \\ Cedex, France \\ ${ }^{2}$ Faculté de Physique, USTHB, BP 32 El-Alia, Dar El Beida, Alger, Algeria \\ ${ }^{3}$ Aperam Alloys Imphy, 58160, Imphy, France \\ ${ }^{4}$ CentraleSupelec Paris, MSSMat, UMR CNRS 8579, Grande Voie des Vignes, 92295 Châtenay- \\ Malabry, France
}

Corresponding author, E-mail: anne-laure.helbert@u-psud.fr.

\begin{abstract}
Plastic deformation of Fe-27\%Co alloy at room temperature was investigated. The present alloy, usually delivered with a low-texture component for the magnetic core in rotating machines, develops a rather high intensity of Goss texture after recrystallization, when a suitable manufacturing process is applied. Thanks to this texture and its magnetic properties, this material can replace the grain-oriented $\mathrm{Fe}-3 \% \mathrm{Si}$ alloy in electric transformer application. The intensity of the recrystallization Goss component depends directly on the sharpness of the $\{111\}<112>$ orientation developed during cold rolling. Thus, the origin of this $\{111\}<112>$ deformation texture has been studied using viscoplastic self-consistent (VPSC) simulations. This model showed that only the $\{110\}<111>$ slip systems allow to develop the $\{111\}<112>$ texture. The predominance of this slip system has been effectively identified from slip markings on the deformed sample by EBSD. More, this simulation has shown that a Goss texture at the hot-rolled state favors the $\{111\}<112>$ development during cold rolling, as observed experimentally.
\end{abstract}

Keywords: Fe-27\%Co alloy; X-ray; EBSD, Rolling, Microscopy, VPSC Simulation,

\section{Introduction}

Due to the increase of the electric loads in the aircraft, the need of power transformers increases. This implies a higher power density of these devices to keep a constant mass in the airplanes. In the case of on-board transformers, an industrial solution to increase the power density is the development new magnetic materials such as iron-cobalt alloys. In particular, Fe-27\%Co exhibits the highest saturation magnetization of all soft ferromagnetic materials $(2,4 \mathrm{~T})$, especially compared to $\mathrm{Fe}-3 \% \mathrm{Si}$ 
alloys currently used (2T) in transformers. More, such as the Fe-3\% Si steel, this alloy can develop the $\{110\}<001>$ Goss texture with an adequate thermo-mechanical processing. The intensity of this texture directly improves the magnetic performances, which is due to the fact that the easy magnetization direction $<001>$ is parallel to the magnetization direction of the sheet (RD) [1].

These properties allow this material to be the best candidate to replace the grain-oriented $\mathrm{Fe}-3 \% \mathrm{Si}$ steel in transportation transformers, requiring high power density.

Many investigations have been focused on the evolution of the Goss texture during the primary and secondary recrystallization of $\mathrm{Fe}-3 \% \mathrm{Si}$ [2-13], where the origin of this Goss component was related to the $\{111\}<112>$ texture, which develops after cold rolling. The cold rolling texture itself was linked to the Goss component of the initial texture developed during hot rolling.

The rotation of components during the plastic deformation of materials occurs thanks to slip mechanisms, where dislocations glide along crystallographic planes (slip planes) and preferred crystallographic directions (slip directions) [14]. For bcc materials, the slip planes are the $\{110\}$, the $\{112\}$, and the $\{123\}$, and the slip direction is only the $<111>$ one. This leads to 48 particular slip systems, 12 related to the $\{110\}<111>$ system, 12 related to the $\{112\}<111>$ system and 24 related to the $\{123\}<111>$ one [15]. Moreover, the plastic deformation can take place by the slip of one or more slip systems, called active slip systems [16-20]. For this purpose, many studies have been focused on the identification of the active slip systems in materials, including bcc materials.

On Fe-Co alloys, an investigation of the plastic deformation behavior of a single crystal of Fe$54 \%$ Co alloy [21] showed that the $\{110\}<111>$ slip system is the active one. Recently [22], a study on the identification of active slip systems in the alpha iron $(\alpha-\mathrm{Fe})$ material by molecular dynamic (MD) simulations was carried out. The authors demonstrated that all slip systems are actives. By doing simulations based on the Taylor model type, Raabe [23] showed that the $\{123\}<111>$ slip system is the predominant active system in the alpha iron $(\alpha-\mathrm{Fe})$. Before these works, it was revealed that the $\{110\}<111>$ is the active slip system in the $\alpha$-Fe [24], while another study [25] showed that, in addition to the $\{110\}<111\rangle$, the $\{112\}<111\rangle$ slip system is also active. Therefore, the results of identification of active slip systems in $\alpha$-Fe are controversial. This can be explained by the different methods used in each study as well as the deformation rates. Other investigations on Mo and W single crystals [26] have demonstrated that the active slip plane, at a low temperature, is the $\{123\}$ one. Moreover, the identification of active slip systems on Fe-Si alloys demonstrated that, during cold rolling, the $\{110\}<111>$ was predominant [27-29]. However, investigations [30-33] have evidenced difficulties to identify the active slip systems in the ferritic phase of a duplex stainless steel. Using optical microscopy, electronic microscopy, and EBSD, the authors supposed that, during the plastic deformation, several slip systems could be active, which makes their detection difficult. These authors assumed that the dislocation slip activity in a grain is not only influenced by its orientation, but also by both the orientation and the slip activity of its neighbors. A recent study mentioned an EBSD 
method to determine the active slip systems in a Ni alloy from the crystal rotation during deformation [34].

Even if some works propose a texture prediction from finite element polycrystal model simulation [35], more conventionally the modeling texture, microstructural evolution, and macroscopic polycrystalline response are often accomplished using the visco-plastic self-consistent (VPSC) polycrystal model [36-38]. The polycrystalline aggregate is represented by several hundred grains, each with a distinct orientation and volume fraction. The VPSC model treats each grain as an ellipsoidal visco-plastic inclusion interacting with the effective medium represented by the average response of all the grains.

This paper aimed to simulate the origin of the cold rolling $\{111\}<112>$ texture via VPSC calculations. This simulation first requires the identification of the active slip systems, not yet known in the Fe-27\% Co alloy, during its cold rolling. The present study allowed the experimental determination of the main slip system, thanks to EBSD analyses coupled with the geometrical calculations of angles associated with these slip systems in the sample coordinate system. Indeed, this numerical modeling has been necessary to determine the slip direction, when the experimental data only provide the slip plane. Thus, combining numerical and experimental approaches, the exact slip system family, activated during cold rolling, has been identified.

VPSC cold rolling simulation was then performed from ideal texture components using the identified slip system to quantify the individual contributions of each component to the $\{111\}<112>$ development.

\section{Material and Methods}

The nominal composition of the alloy is $\mathrm{Fe}-27 \% \mathrm{Co}-0.5 \% \mathrm{Cr}$ (wt.\%). The sheet was prepared at Aperam Alloys Imphy industry and is called AFK1. The thermomechanical process used to fabricate the AFK1 sheet includes a hot rolling to a thickness reduction of $2.5 \mathrm{~mm}$, followed by a doubling cold rolling of $70 \%$ of thickness reduction and then three cumulative annealing treatments at $930{ }^{\circ} \mathrm{C}$. The thickness of the final sheet is approximately $0.2 \mathrm{~mm}$. Along this processing route, it has been observed that during annealing treatments, the $\{111\}<112>$ intensity remains quite low while the Goss fraction increases. On the contrary, the $\{111\}<112>$ orientations develop during cold rolling.

The local texture was carried out by EBSD and the global one was measured by X-ray diffraction. The EBSD results were collected using a scanning electron microscope Zeiss FEG SUPRA 55VP operating at $20 \mathrm{kV}$ and equipped with an $\mathrm{OIM}^{\mathrm{TM}}$ system. X-ray data were collected from a Siemens system $\left(\mathrm{K}_{\alpha}\right.$ cobalt radiation) and the $\{110\},\{200\}$, and $\{112\}$ incomplete pole figures were recorded. The data were then analyzed using the arbitrarily defined cells (ADC) method implemented in the Labotex software to calculate the complete pole figures and the orientation distribution function. The 
samples analyzed by EBSD were first mechanically polished and then electro-polished (Struers A2 solution) at $22{ }^{\circ} \mathrm{C}$, with a voltage of $15 \mathrm{~V}$ for $12 \mathrm{~s}$.

EBSD maps of $\left(770 \times 2300 \mu \mathrm{m}^{2}\right)$ were measured with a step size of $1 \mu \mathrm{m}$. The slip systems identification was particularly performed on partitions of acquired points belonging only to grains exhibiting the $[111]<1 \overline{2} 1>$ and $[111]<\overline{1} \overline{1} 2>$ orientations with a dispersion of $15^{\circ}$ around the ideal position. The experimental identification of active slip systems was based on the method reported in the literature [30-33, 39], applied in the case of duplex stainless steel. These authors compared values of $\alpha$ angle (Fig. 1), obtained by measurements on the SEM pictures, and those calculated from Eq. (1) using Euler angles and for all the potential active slip systems. $\alpha$ corresponds to the angle between the slip plane marking in the rolling surface and the rolling direction (RD). In addition, they calculated the corresponding Schmid factor and a second angle between the slip direction and the normal to the slip plane surface. Contrary to the austenitic phase (fcc), the authors revealed some inconsistencies in the calculation of the Schmid factor for the ferritic phase (bcc); moreover, they found that an $\alpha$ angle could correspond to different slip planes. In this work, the same inconsistencies have been found. Then, a second angle named $\beta$ was introduced into the calculations using Eq. (2). As shown in Fig. 1, $\beta$ corresponds to the angle between the slip markings in the (RD, ND) surface and the loading axis in the normal direction $\left(\sigma_{\mathrm{ND}}\right)$. This angle enables the identification of the active slip plane and moreover, it allows to dissociate the slip planes having the same angle $\alpha$.

As it can be observed in Fig. 1, the intersection between the slip plane and the rolling surface (RD, TD) can be obtained by calculating the scalar product between $\overrightarrow{\sigma_{R D}}$ and $\vec{X}$, where $\vec{X}$ is the vector product between $\overrightarrow{n_{s p}}$ and $-\overrightarrow{\sigma_{N D}}$.

Therefore, $\cos \alpha$ can be expressed as:

$$
\cos \alpha=\left[\frac{\left(\overrightarrow{n_{s p}} \wedge-\overrightarrow{\sigma_{N D}}\right)}{\left\|\left(\overrightarrow{n_{s p}} \wedge-\overrightarrow{\sigma_{N D}}\right)\right\|} \frac{\overrightarrow{\sigma_{R D}}}{\left\|\overrightarrow{\sigma_{R D}}\right\|}\right]
$$

The second angle $\beta$ can be expressed by the relation:

$$
\cos \beta=\vec{w} \times \overrightarrow{\sigma_{N D}}
$$

Then, for each possible slip system, two angles $\alpha$ and $\beta$ are calculated. The comparison between these two calculated angles and the experimental values measured on the EBSD maps will allow the activated slip planes to be identified.

\section{Texture simulation based on VPSC scheme (Visco-plastic self-consistent)}

The present simulations are based on the VPSC scheme [40]. Different models incorporated in the VPSC package were proven robust because they could predict the flow curves, texture evolution, 
anisotropy, forming-limit strains of metals as well as actual active deformation mechanisms [41-42]. Molinari et al. [40] developed the VPSC formulation for large strain deformation in which each grain is treated as an ellipsoidal visco-plastic inclusion embedded in a viscoplastic homogeneous equivalent medium (HEM). Both inclusion and HEM have fully anisotropic properties. The HEM represents the average environment seen by each grain. A more general formulation with an anisotropic medium was introduced [43]. The interaction between the grain and the HEM is carried out by a visco-plastic Eshelby approach [44]. Deformation is based on crystal plasticity mechanisms, where slip and twinning systems are activated by a critical resolved shear stress (CRSS).

In this section, some equations of this VPSC scheme will be presented. More details can be found in papers of Lebensohn and Tomé [43] and Molinari et al. [40]. The viscoplastic constitutive behavior at the local level in a given grain is described by means of the non-linear rate-sensitivity and given by Eq. (3):

$$
\dot{\epsilon}_{i j}(\bar{x})=\sum_{s} m_{i j}^{s} \dot{\gamma}^{s}(\bar{x})=\dot{\gamma}_{0} \sum_{s} m_{i j}^{s}\left(\frac{m_{k l}^{s} \sigma_{k l}(\bar{x})}{\tau^{s}}\right)^{n}
$$

$\tau^{S}$ is the threshold stress controlling the activation of a slip system , $m_{i j}^{S}$ is the symmetric Schmid tensor associated with the slip system $(\mathrm{s}), \dot{\epsilon}_{i j}(\bar{x})$ and $\sigma_{k l}(\bar{x})$ are the deviatoric strain-rate and stress, and $\dot{\gamma}^{s}(\bar{x})$ is the local shear-rate on the slip system, $\dot{\gamma}_{0}$ is a normalizing strain rate and $n$ is the strainrate sensitivity for the crystallographic slip.

The slip will occur in a system $s$ when the resolved shear stress $m_{k l}^{s} \sigma_{k l}(\bar{x})$ approaches the critical value $\tau^{s}$.

The empirical Voce law that describes the evolution of the critical stress value with deformation due to self and latent hardening for an individual slip system is given by:

$$
\tau^{s}=\tau_{0}^{S}+\left(\tau_{1}^{S}+\theta_{1}^{S} \Gamma\right)\left\{1-\exp \left(-\frac{\theta_{0}^{S} \Gamma}{\tau_{1}^{s}}\right)\right\}
$$

$\tau_{0}^{S}$ and $\theta_{0}^{S}$ describe the initial flow stress and the initial hardening rate, respectively. The parameters $\tau_{1}^{s}$ and $\theta_{1}^{s}$ describe the asymptotic characteristic of the hardening. $\Gamma$ is the total accumulated shear strain in a grain:

$$
\Gamma=\int_{0}^{t} \Sigma_{s}\left|\dot{\gamma}^{s}\right| d t
$$

$\dot{\gamma}^{s}$ is the shear rate on slip system s.

The Voce hardening parameters used in this paper are thus: $\tau_{0}^{s}=1 M P a, \tau_{1}^{s}=0 M P a, \theta_{0}^{s}=$ $1 M P a$, and $\theta_{1}^{S}=1 M P a$, which correspond to a linear hardening [43, 45]. The strain-rate sensitivity is taken such that $n=20$. Indeed, this relatively large value for cold deformation is used to speed up the calculation process and does not alter the texture in comparison to lower values [40]. Then, the 
deformation is simulated by imposing successive deformation increments (in 50 increments) till von Mises strain $\varepsilon=1.2$. At each deformation step, the boundary conditions, in terms of the overall velocity gradient corresponding to the constant strain rate, are imposed. The applied velocity gradient tensor is for plane strain compression:

$$
L=\left[\begin{array}{ccc}
1 & 0 & 0 \\
0 & 0 & 0 \\
0 & 0 & -1
\end{array}\right]
$$

In order to explore the influence of different slip systems known to be active within Fe-27\%Co alloy $(\{110\}<111>,\{112\}<111>$ and $\{123\}<111>)$ on the experimental resulted texture only one system was considered during each simulation. Thus, the latent hardening effects was not considered, i.e., coupling shear increments in one glide system $s$ with the increase in strength in another system $s^{\prime}$. It is to be noted that CRSS values are assumed to be equal for all slip families systems.

To analyze the effects of different texture components on the evolution of deformation texture during cold rolling of $\mathrm{Fe}-27 \% \mathrm{Co}$ alloy four initial texture represented by a set of 2000 orientations were assumed: a random texture, the Rotated Cube $\{001\}<110>$ texture, the Goss $\{110\}<001>$ texture and a texture composed of two components (Rotated Cube + Goss) with equal volume fraction. For each texture component, a dispersion of $15^{\circ}$ was used for texture generation.

\section{Results}

\subsection{Experimental results}

As mentioned above, in Fe-Si alloys, magnetic induction is directly linked to the Goss sharpness. More, a relationship exists between the $\{111\}<112>$ cold rolling texture and the Goss after the final recrystallization annealing. This dependence of magnetic properties with the $\{111\}<112>$ intensity after cold rolling is confirmed for several initial hot rolling (HR) conditions for the present Fe-27\%Co alloy (Fig. 2).

\subsubsection{Origin of the $\{111\}<112>$ cold rolling texture}

Four samples achieved from four different hot rolling conditions were studied before and after the first $70 \%$ cold rolling. Fig. 3 shows the evolution of the deformation texture (X-ray diffraction measurement in the (RD, TD) plane) compared to the initial texture (EBSD measurement in the (RD, ND) plane to take into account the texture inhomogeneity through thickness) and represented by the ODF sections at $\varphi_{2}=45^{\circ}$. It has been shown in a previous study [46] that all these initial textures change into Goss texture, more or less sharp, after cold rolling followed by annealing treatment.

The most relevant bcc rolling texture components are situated along the alpha -fiber: $\{\mathrm{hkl}\}<110\rangle$ $\left(\varphi_{1}=0^{\circ}, \varphi_{2}=45^{\circ}\right)$, consisting of the rotated Cube component, the $\left.\{001\}<110\right\rangle\left(\phi=0^{\circ}\right)$, the $\{112\}<110\rangle\left(\phi=35^{\circ}\right)$, and the $\left.\{111\}<110\right\rangle\left(\phi=55^{\circ}\right)$ as well as along the gamma-fiber: 
$\{111\}<\mathrm{uvw}>$, consisting of the $\{111\}<110>\left(\varphi_{1}=0^{\circ}\right.$ and $\left.60^{\circ}, \phi=55^{\circ}, \varphi_{2}=45^{\circ}\right)$ and the $\{111\}<112>$ $\left(\varphi_{1}=30^{\circ}\right.$ and $\left.90^{\circ}, \phi=55^{\circ}, \varphi_{2}=45^{\circ}\right)$. After cold rolling, the texture is characterized mainly by both the alpha and gamma fiber components, including the $\{111\}<112>$ orientation. Such texture has been already observed in bcc alloys [12,47]. It can be observed from Fig. 3c that when the initial texture exhibits a marked Goss component, the cold rolling is characterized by a higher-intensity $\{111\}<112>$ component. It could be concluded that the Goss orientation acts as a starting texture for the development of the $\{111\}<112>$ component after plastic deformation. This is consistent with results in the literature on Fe-Si single crystals initially Goss oriented [6,47]. Moreover, when the initial texture is characterized by only a reinforcement around the rotated Cube (Fig. 3d), the cold rolling implies also a development of the $\{111\}<112\rangle$ orientation, but with lower intensity. Despite this lower intensity, the Goss texture of the primary recrystallization develops [45]. This shows that during the plastic deformation of AFK1 alloy, in addition to the Goss texture, the rotated Cube is also an origin for the development of the $\{111\}<112>$ orientation. However, looking at the intensities of the $\{111\}<112>$ component (Fig. 3), it appears that the rotated Cube (Fig. 3d) in the initial texture less favors the $\{111\}<112>$ development than the Goss does (Fig. 3c). In parallel, when the initial texture is random (Fig. 3a), the cold rolling texture also develops the $\{111\}<112>$ component, which exhibits close intensity value to that one generated from the rotated Cube.

As a consequence, the Goss, the rotated Cube, and some minor components in the random texture generate the $\{111\}<112>$ texture component during the plastic deformation by cold rolling of the AFK1 material.

\subsubsection{Measurements of the $\alpha$ and $\beta$ angles}

After a cold rolling to a nominal $70 \%$ thickness reduction, the microstructure of the AFK1 alloy is characterized by elongated $\{111\}<112>$ deformed grains parallel to the rolling direction (RD) (Figs. 4 and 5). Let us note that figures 4 and 5 are described in the (RD, TD) and (RD, ND) planes, respectively. These deformed grains are characterized by slip markings, which correspond to the trace of active slip planes. Obviously, it is assumed that what is seen at the end of the cold rolling is representative of the main dislocation activity during the entire process. The measurements of the $\alpha$ and $\beta$ angles for both the (111)[12 1 ] and (111)[ $\overline{1} \overline{1} 2]$ symmetric orientation grains exhibit values of $90^{\circ} \pm 5^{\circ}$ and $73^{\circ} \pm 5^{\circ}\left(\alpha\right.$ angle) (Fig. 4), and $60 \pm 5^{\circ}(\beta$ angle) (Fig. 5). Due to the non-linearity of the slip markings in the surface (RD, TD), it is difficult to get an exact value of $\alpha$ angle. However, a trend of two values from a large static number of traces is extracted $\left(90^{\circ} \pm 5^{\circ}\right.$ and $\left.73^{\circ} \pm 5^{\circ}\right)$. 


\subsubsection{Calculations of the $\alpha$ and $\beta$ angles}

The results of the calculation of angles $\alpha$ and $\beta$ using Eqs. (1) and (2) are shown in Fig. 6. Experimentally, only 2 combinations of angles $\alpha$ and $\beta$ have been observed: $\left(90^{\circ} ; 60^{\circ}\right)$ and $\left(73^{\circ} ; 60^{\circ}\right)$. They coincide with two calculated $\alpha$ and $\beta$ values. These values correspond to two particular slip planes, the (110) and $(01 \overline{1})$. These slip planes are associated with four possible active slip systems: the (110)[1 $\overline{1} 1]$, the $(110)[\overline{1} 11]$, the $(01 \overline{1})[111]$ and the $(01 \overline{1})[\overline{1} 11]$ systems.

In conclusion, based on the comparison between experimental identification and analytic calculation, the $\{110\}<111>$ is a predominant active family of slip systems in the $\mathrm{Fe}-27 \% \mathrm{Co}$ after a cold rolling to a nominal $70 \%$ thickness reduction. However, the non-linearity of slip markings in (RD, TD) could be related to the influence of other active slip systems, which are probably active but exhibit minor activity.

\subsection{Results of simulations based on VPSC scheme}

The VPSC simulations (Fig. 7) demonstrated that whatever the starting texture, the cold rolling one is reinforced around the $\{111\}<112>$ component when the slip systems $\{110\}<111>$ are active as experimentally observed. On the contrary, when this is inactive, the cold rolling develops a texture reinforced rather on the $\{111\}<110>\gamma$ fiber component. The main interesting results of this study are shown in Fig. 8.

Thanks to these simulations, it is possible to quantify the $\{111\}<112>$ fraction (with a dispersion of $15^{\circ}$ ) developed during cold rolling depending on the initial texture (Fig. 9). As experimentally observed (Fig. 3), a higher fraction of the $\{111\}<112\rangle$ component is obtained when the Goss orientation is present in the starting texture. However, the initial random texture develops also the $\{111\}<112>$ orientation such as the rotated Cube one.

For an initial texture of $100 \%$ of Goss or $100 \%$ of rotated Cube, the $\{111\}<112>$ exhibits fractions of $46 \%$ and $32 \%$, respectively. These fractions correspond to contribution factors of 0.46 and 0.32 , respectively in Eq.7. In a first approximation, this equation allows one to estimate the $\{111\}<112>$ fraction from this of components present in the initial texture.

$$
\mathrm{f}_{(\text {Recalculated }\{111\}<112>)}=0.46 \times \mathrm{f}_{\text {Goss }}+0.32 \times \mathrm{f}_{\text {rotated-Cube }}+\mathrm{x} \times \mathrm{f}_{\text {random }}
$$

The contribution of the random part $(\mathrm{x})$ cannot be calculated directly from the random initial texture in Fig. 9 because it contains the Goss and rotated Cube components. Then, the random contribution has been estimated from the different experimental initial textures of Fig. 3, by knowing the experimental fraction of the main components ( $\left.f_{\text {Goss }}, f_{\text {rotated-Cube }}\right)$ and the associated experimental fractions of $\{111\}<112>$ orientation after cold rolling. The contribution of the random part was 
estimated to an approximate value of $0.15+/-0.02$. Figure 10 shows a quite good agreement between the $\{111\}<112>$ fractions measured from figure 3 and the calculated values from Eq.7. The difference between experimental and simulation results could provide first from the estimation of $x$ (Eq.7) that is calculated thanks to 4 different initial textures while a larger number of textures could have been helpful to get a more accurate $x$ value, second from the linear assumption in Eq.7. Finally, this difference could be due to the possible activation of secondary slip systems not taken into account in the simulation. Despite these limitations, Eq.7 is somehow able to predict the experimental fraction of $\{111\}<112>$ regardless of the initial texture knowing the Goss, rotated Cube and random fractions within this texture. This is of high industrial interest.

Therefore, from the comparison between measurements and simulations based on VPSC scheme, it may be concluded that during the cold rolling, the $\{111\}<112>$ component develops from the rotation of the Goss, rotated Cube, and some minor random components present in the initial texture. This occurs when the $\{110\}<111>$ system is active.

\section{Discussion}

Studies on single crystals of Fe-Si alloys showed that the $\{111\}<112>$ orientation is the result of a $35^{\circ}$ rotation of the initial Goss texture around the transverse direction (TD) [6,47]. The present study shows that in addition to the initial Goss texture, the cold rolling texture develops also from the rotated Cube component, the $\{001\}<110\rangle$. Moreover, other components from the random part in the initial texture contribute as well to the development of the cold-rolled orientation $\{111\}<112>$. In parallel, it has been demonstrated that the Goss texture implies a higher intensity of the $\{111\}<112>$ component than the rotated Cube. The rotation of these initial components to the $\{111\}<112>$ occurs when the $\{110\}<111>$ is the predominant active family of slip systems. In respect to the identification of active slip systems, the results of this paper show good agreement with many results in the literature on the identification of active slip systems in bcc materials [24,27-29], particularly with those of Yamaguchi et al. [21] on Fe-54\%Co single crystal despite the fact that this alloy can be B2 ordered [48-49]. This leads to the hypothesis that the Fe-Co alloys may have the same slip mechanism behavior at room temperature, where many slip systems could be activated, with a predominance of the $\{110\}<111>$ slip systems (see also [50]).

In regards to the rotation of the Goss and rotated Cube to the $\{111\}<112>$ component during the plastic deformation of AFK1, explanations based on crystallographic considerations are proposed. It should be recalled that, on one hand, the $\{110\}$ is the slip plane and the final texture is characterized by the $\{111\}$ plane parallel to the rolling surface (RD, TD) and on the other hand, the angle between the $\{110\}$ and the $\{111\}$ planes is $35^{\circ}$ (Fig. 10). To facilitate the dislocations gliding, the $\{110\}$ plane of the Goss and the rotated Cube components must be placed on the favorable position of gliding to maximize the Schmid factor value. This position corresponds to a deviation of $35^{\circ}$ from the rolling 
surface (so $55^{\circ}$ from the normal one (ND, TD)). Experimentally, the trace of slip planes was observed at $60^{\circ}$ from the normal surface, which is in good agreement. The deviation of $5^{\circ}$ can be explained by the activation of the other slip systems.

Thus, a rotation of $35^{\circ}$ around the transverse direction is sufficient for the Goss component to place the $\{110\}$ plane into the favorable position of gliding (Fig. 11). This value of $35^{\circ}$ is consistent with previous studies on single crystals of Fe-Si $[6,47,51]$. Regarding the rotated Cube component, it must rotate of $55^{\circ}$ about the same axis TD to place the slip plane into the favorable position of gliding. The different values of rotation angles between the two components explains why it is easier to form the $\{111\}<112>$ texture from the Goss component than the rotated Cube.

\section{Conclusion}

The magnetic properties of the Fe-27\% Co, at least along the rolling direction, is governed by its ability to develop the Goss texture during annealing. This component is obtained from the $\{111\}<112>$ orientation present after cold rolling. The generation of this component during cold rolling is thus of great interest and has been explained experimentally and using VPSC calculations as follows:

- The Goss $\{110\}<001>$ and rotated Cube $\{001\}<110>$ components and some minor random components are at the origin of the cold-rolled $\{111\}<112>$ texture development.

- During the plastic deformation of the Fe-27\%Co alloy, at room temperature, the $\{110\}<111>$ slip systems have been experimentally evidenced as the predominant ones.

- To place the predominant active slip plane, the $\{110\}$, into the favorable position for gliding (55 from the normal direction), which corresponds to the maximum Schmid factor value, both the rotated Cube and the Goss components must turn around the transverse direction by $55^{\circ}$ and $35^{\circ}$, respectively. Therefore, a higher-intensity $\{111\}<112>$ component could be obtained, especially when the initial texture is mainly Goss, which requires less rotation.

- The VPSC simulations have demonstrated that the only way to produce a cold-rolled $\{111\}<112>$ texture is to activate the $\{110\}<111>$ slip systems.

\section{Acknowledgements}

Authors wish to thank R. Batonnet from Aperam alloys industry, for providing all the samples of the investigated Fe-27\%Co alloy. This work was supported by "La region Ile de France" and in part by the PHC Tassili program No. 12MDU862 and another part by the PHC Maghreb program $\mathrm{N}^{\circ}$ 16MAG03. The authors would also like to thank Carlos N. Tomé from Los Alamos National Laboratory, USA (tome@lanl.gov) for providing VPSC7 code. 


\section{References}

1. R. Bozorth, Ferromagnetism, Ferromagn. by Richard M. Bozorth, pp. 992, 1993, 74, p 115149 ,

http://dx.doi.org/10.1002/9780470386323.ch4\%5Cnhttp://adsabs.harvard.edu/abs/1993f err.book.......

2. N. Bernier, E. Leunis, C. Furtado, T. Van De Putte, and G. Ban, EBSD Study of Angular Deviations from the Goss Component in Grain-Oriented Electrical Steels, Micron, 2013, 5455, p 43-51.

3. F. Cruz-Gandarilla, T. Baudin, R. Penelle, and H. Mendoza-Leon, "Study of Local Microstructure and Texture Heterogeneities in Hot Rolled CGO Fe-3\%Si Sheets," Materials Science Forum, 2004, p 123-128, http://www.scopus.com/inward/record.url?eid=2-s2.017144375595\&partnerID=tZOtx3y1.

4. F. Cruz-Gandarilla, R. Penelle, H.M. Leon, T. Baudin, and J.G. Cabañas-Moreno, "A Study of Local Microstructure and Texture Heterogeneities in a CGO Fe3\%Si Alloy from Hot Rolling to Primary Recrystallization," Materials Science Forum, 2005, p 483-488, http://www.scopus.com/inward/record.url?eid=2-s2.0-35348868606\&partnerID=tZOtx3y1.

5. F. Cruz-Gandarilla, R. Penelle, H.M. Leon, T. Baudin, and J.G. Cabañas-Moreno, "Texture and Microstructure Evolution in a Fe-Si CGO Sheet during the Processing Route before Secondary Recrystallization", 2008, Ed. A.D. Rollett, John Wiley \& Sons, Hoboken, NJ, USA.

6. C.G. Dunn, "Cold-rolled and primary recrystallization textures in cold-rolled single crystals of silicon iron", Acta Metall, 1954, 2, p 173-183.

7. C. Gheorghies and A. Doniga, Evolution of Texture in Grain Oriented Silicon Steels, J. Iron Steel Res. Int., 2009, 16(4), p 78-83.

8. W. Guo, W. min Mao, Y. Li, and Z.G. An, Influence of Intermediate Annealing on Final Goss Texture Formation in Low Temperature Reheated Fe-3\%Si Steel, Mater. Sci. Eng. A, 2011, 528(3), p 931-934.

9. Y. Inokuti, YShimizu, C. Maeda, and H. Shimanakai, "Method of producing grain oriented silicon steel sheets or strips having high magnetic induction and low iron loss", Proceedings of the 1st Riso Intenational Symposium on Metallurgy and materials sciences, 1980.

10. H. Masui, Y. Matsuo, M. Mizokami, and H. Mogi, Relation between Magnetostriction and Magnetic Domains in Changing Direction of Grain Oriented Silicon Steel Sheet, ISIJ Int. 1996, 36(1), p 101-110, doi:10.2355/isijinternational.36.101.

11. M. Matsuo, Texture Control in the Production of Grain Oriented Silicon Steels., ISIJ Int., 1989, 29(10), p 809-827, doi:10.2355/isijinternational.29.809.

12. S. Mishra, C. Därmann, and K. Lücke, On the Development of the Goss Texture in Iron-3\% Silicon, Acta Metall., 1984, 32(12), p 2185-2201.

13. V. Stoyka, F. Kováč, O. Stupakov, and I. Petryshynets, Texture Evolution in Fe-3\% Si Steel Treated under Unconventional Annealing Conditions, Mater. Charact., 2010, 61(11), p 1066-1073.

14. P. Chen, S.C. Mao, Y. Liu, F. Wang, Y.F. Zhang, Z. Zhang, and X.D. Han, In-Situ EBSD Study of the Active Slip Systems and Lattice Rotation Behavior of Surface Grains in Aluminum Alloy during Tensile Deformation, Mater. Sci. Eng. A, 2013, 580, p 114-124.

15. D. Raabe, and K. Lücke, "Rolling and Annealing Textures of BCC Metals", Materials Science Forum, 1994, 157, p 597-610.

16. F. Bridier, D.L. McDowell, P. Villechaise, and J. Mendez, Crystal Plasticity Modeling of Slip Activity in Ti-6Al-4V under High Cycle Fatigue Loading, Int. J. Plast., 2009, 25(6), p 10661082.

17. E.P. Busso and G. Cailletaud, "On the Selection of Active Slip Systems in Crystal Plasticity," International Journal of Plasticity, 2005, p 2212-2231.

18. B. Klusemann, B. Svendsen, and H. Vehoff, Modeling and Simulation of Deformation 
Behavior, Orientation Gradient Development and Heterogeneous Hardening in Thin Sheets with Coarse Texture, Int. J. Plast., 2013, 50, p 109-126.

19. J.R. Mayeur, I.J. Beyerlein, C.A. Bronkhorst, H.M. Mourad, and B.L. Hansen, A Crystal Plasticity Study of Heterophase Interface Character Stability of $\mathrm{Cu} / \mathrm{Nb}$ Bicrystals, Int. J. Plast., 2013, 48, p 72-91.

20. P.A. Sabnis, S. Forest, N.K. Arakere, and V.A. Yastrebov, Crystal Plasticity Analysis of Cylindrical Indentation on a Ni-Base Single Crystal Superalloy, Int. J. Plast., 2013, 51, p 200-217.

21. M. Yamaguchi, Y. Umakoshi, T. Yamane, Y. Minonishi, and S. Morozumi, Slip Systems in an Fe-54 At. \% Co Alloy, Scr. Metall., 1982, 16(5), p 607-609.

22. N. Naveen Kumar, R. Tewari, P. V. Durgaprasad, B.K. Dutta, and G.K. Dey, Active Slip Systems in Bcc Iron during Nanoindentation: A Molecular Dynamics Study, Comput. Mater. Sci., 2013, 77, p 260-263.

23. D. Raabe, Experimental Investigation and Simulation of Crystallographic Rolling Textures of Fe-11Cr Steel, Mater. Sci. Technol., 1995, 11(10), p 985-993, doi:10.1179/mst.1995.11.10.985.

24. J.J. Cox, G.T. Horne, and R.F. Mehl, Slip, Twinning and Fracture in Single Crystals of Iron, Trans. Am. Soc. Met., 1957, 49, p 118-131.

25. W.A. Spitzig and A.S. Keh, The Effect of Orientation and Temperature on the Plastic Flow Properties of Iron Single Crystals, Acta Metall., 1970, 18(6), p 611-622.

26. D. Ali, M.Z. Butt, and M. Khaleeq-Ur-Rahman, Ablation Yield and Angular Distribution of Ablated Particles from Laser-Irradiated Metals: The Most Fundamental Determining Factor, Appl. Surf. Sci., 2011, 257(7), p 2854-2860.

27. D. Hull, "Orientation and temperature dependence of plastic deformation processes in $3.25 \%$ Silicon Iron", Proc. R. Soc. Lond., 1963, 274, p 5-20.

28. B. Šesták and J. Blahovec, The Temperature Dependence of Slip Planes in Fe-3.4\% Si Single Crystals, Phys. status solidi, 1970, 40(2), p 599-607.

29. T. Taoka, S. Takeuchi, and E. Furubayashi, Slip Systems and Their Critical Shear Stress in 3\% Silicon Iron, J. Phys. Soc. Japan, 1964, 19(5), p 701-711.

30. A. El Bartali, "Apport des mesures de champs cinématiques à l'étude des micromécanismes d'endommagement en fatigue plastique d'un acier inoxydable duplex", Ph.D. Dissertation, Ecole centrale de Paris, Paris, France, 2007, in french.

31. A. El Bartali, V. Aubin, L. Sabatier, P. Villechaise, and S. Degallaix-Moreuil, Identification and Analysis of Slip Systems Activated during Low-Cycle Fatigue in a Duplex Stainless Steel, Scr. Mater., 2008, 59(12), p 1231-1234.

32. A. El Bartali, V. Aubin, and S. Degallaix, Surface Observation and Measurement Techniques to Study the Fatigue Damage Micromechanisms in a Duplex Stainless Steel, Int J Fatigue, 2009, 31(11--12), p 2049-2055, doi:10.1016/j.ijfatigue.2008.11.003.

33. M.C. Marinelli, A. El Bartali, J.W. Signorelli, P. Evrard, V. Aubin, I. Alvarez-Armas, and S. Degallaix-Moreuil, Activated Slip Systems and Microcrack Path in LCF of a Duplex Stainless Steel, Mater. Sci. Eng. A, 2009, 509(1-2), p 81-88.

34. X. Zheng and H. Zhang, Experimental Determination of Deformation Induced Lattice Rotation by EBSD Technique for Slip System Analysis, J. Mater. Sci. Technol., 2017, 33(1), p 90-98.

35. C. Liqing and N. Kanetake, Experimental Study and Finite Element Polycrystal Model Simulation of the Cold Rolling Textures in a Powder Metallurgy Processed Pure Aluminum Plate, J. Mater. Sci. Technol., 2005, 21(2), inspec:8461481.

36. R.A. Lebensohn and C.N. Tomé, A Self-Consistent Anisotropic Approach for the Simulation of Plastic Deformation and Texture Development of Polycrystals: Application to Zirconium Alloys, Acta Metall. Mater., 1993, 41(9), p 2611-2624.

37. U.F.Kocks, C.N. Tome, and H.R. Wenk, "Texture and Anisotropy. Preferred Orientations in Polycrystals and Their Effect on Materials Properties", 2nd edition, Cambridge: Cambridge 
University Press, UK, 2000.

38. I.J. Beyerlein, R.A. Lebensohn, and C.N. Tomé, Modeling Texture and Microstructural Evolution in the Equal Channel Angular Extrusion Process, Mater. Sci. Eng. A, 2003, 345(12), p 122-138, doi:10.1016/S0921-5093(02)00457-4.

39. P. Mu, "Etude de l'amorçage en fatigue plastique d'un acier inoxydable austénitique. Ph.D. Dissertation", Ecole Centrale de Lille, France, 2011, in french.

40. A. Molinari, G.R. Canova, and S. Ahzi, A Self Consistent Approach of the Large Deformation Polycrystal Viscoplasticity, Acta Metall., 1987, 35(12), p 2983-2994.

41. H. El Kadiri, J.C. Baird, J. Kapil, A.L. Oppedal, M. Cherkaoui, and S.C. Vogel, Flow Asymmetry and Nucleation Stresses of $\left\{\begin{array}{llll}1 & 0 & 1\end{array}\right\}$ Twinning and Non-Basal Slip in Magnesium, Int. J.

Plast., 2013, 44, p 111-120.

42. K. Kitayama, C.N. Tomé, E.F. Rauch, J.J. Gracio, and F. Barlat, A Crystallographic Dislocation Model for Describing Hardening of Polycrystals during Strain Path Changes. Application to Low Carbon Steels, Int. J. Plast., 2013, 46, p 54-69.

43. R.A. Lebensohn and C.N. Tomé, A Self-Consistent Viscoplastic Model: Prediction of Rolling Textures of Anisotropic Polycrystals, Mater. Sci. Eng. A, 1994, 175(1-2), p 71-82.

44. J.D.Eshelby, "Determination of the elastic field of an ellipsoidal inclusion", Proc. R. Soc. Lond., 1957, 241, p 376-396.

45. C. Tomé, G.R. Canova, U.F. Kocks, N. Christodoulou, and J.J. Jonas, The Relation between Macroscopic and Microscopic Strain Hardening in F.C.C. Polycrystals, Acta Metall., 1984, 32(10), p 1637-1653.

46. Nabi B., "Nouveaux alliages Fe-Co magnétiques pour l'aéronautique, à microstructure partiellement recristallisée et à texture fortement orientée", Ph.D. Dissertation, Université Paris-Sud, France, 2014, in french.

47. D. Dorner, S. Zaefferer, and D. Raabe, Retention of the Goss Orientation between Microbands during Cold Rolling of an Fe3\%Si Single Crystal, Acta Mater., 2007, 55(7), p 2519-2530.

48. B. Nabi, A.-L. Helbert, F. Brisset, G. André, T. Waeckerlé, and T. Baudin, Effect of Recrystallization and Degree of Order on the Magnetic and Mechanical Properties of Soft Magnetic FeCo-2V Alloy, Mater. Sci. Eng. A, 2013, 578.

49. B. Nabi, A.-L. Helbert, F. Brisset, R. Batonnet, G. André, T. Waeckerlé, and T. Baudin, Effect of Long Range Order on Mechanical Properties of Partially Recrystallized Fe49Co-2V Alloy, Mater. Sci. Eng. A, 2014, 592.

50. D. Ali, N. Mushtaq, and M.Z. Butt, Investigation of Active Slip-Systems in Some Body-Centered Cubic Metals, J. Mater. Sci., 2011, 46(11), p 3812-3821.

51. D. Dorner, S. Zaefferer, L. Lahn, and D. Raabe, Overview of Microstructure and Microtexture Development in Grain-Oriented Silicon Steel, J. Magn. Magn. Mater., 2006, 304(2), p 183-186. 


\section{Figure captions}

Fig. $1 \alpha$ is the angle between the slip plane marking in the rolling surface (RD, TD) and RD axis. $\beta$ is the angle between the slip plane marking in the normal plane (RD, ND) and the ND axis.

$\overrightarrow{n_{s p}}$ : the normal to the slip plane. $\vec{w}$ : the parallel vector to the slip marking, observed in the normal plane to the rolling surface (RD, ND).

Fig. 2 Evolution of the magnetic induction B10Oe and the $\{111\}<112>$ fraction for samples with different initial hot rolling (HR) conditions.

Fig. 3 Texture before and after the first 70\% cold rolling of AFK1 alloy as a function of 4 different initial textures: $a, b, c$ and $d$. ODF representation, section at $\varphi_{2}=45^{\circ}$.

Fig. 4 Measurements of $\alpha$ angle on the surface (RD, TD) of the cold rolled AFK1, by EBSD technique. (a) IQ map, (b) partition of points having (111)[1리] and (111)[ $\overline{1} \overline{1} 2]$ orientations with a dispersion of $15^{\circ}$ around the ideal position, (c) map of $\{\mathrm{hkl}\}$ planes parallel to the rolling plane (RD, TD) (the scale bar is $300 \mu \mathrm{m}$ ).

Fig. 5 Measurements of angle $\beta$ on the surface (RD, ND) of the cold rolled AFK1, measured by EBSD technique. (a) IQ map, (b) partition of points having the (111)[1 $\overline{2} 1]$ and (111)[ $\overline{1} \overline{1} 2]$ orientations with a dispersion of $15^{\circ}$ around the ideal position, (c) map of $\{\mathrm{hkl}\}$ planes parallel to the rolling plane (RD, TD) (The scale bar is $60 \mu \mathrm{m}$ ).

Fig. 6 Comparison between values of measured and calculated $\alpha$ and $\beta$ angles.

Fig. 7 VPSC simulation of the evolution of the cold rolling texture as a function of different starting texture components (color bar is defined between levels 1 and 20).

Fig. 8 Scheme of the evolution of the cold rolling texture as a function of both the starting texture and the active families of slip systems simulated using the VPSC model.

Fig. 9 Evolution of fractions of the cold rolled component $\{111\}<112>$ as a function of the initial texture. Results obtained by simulations based on VPSC model for each family of active slip systems $\{110\}<111>$.

Fig. 10 Comparison between the recalculated (Eq. (7)) and experimental $\{111\}<112\rangle$ fractions after cold rolling depending on the experimental initial textures from Fig. 3. The dispersion around the ideal position is $15^{\circ}$.

Fig. 11 Ideal stereographic projection of the three principal investigated components, on $\{011\}$ pole figure. 
Figures

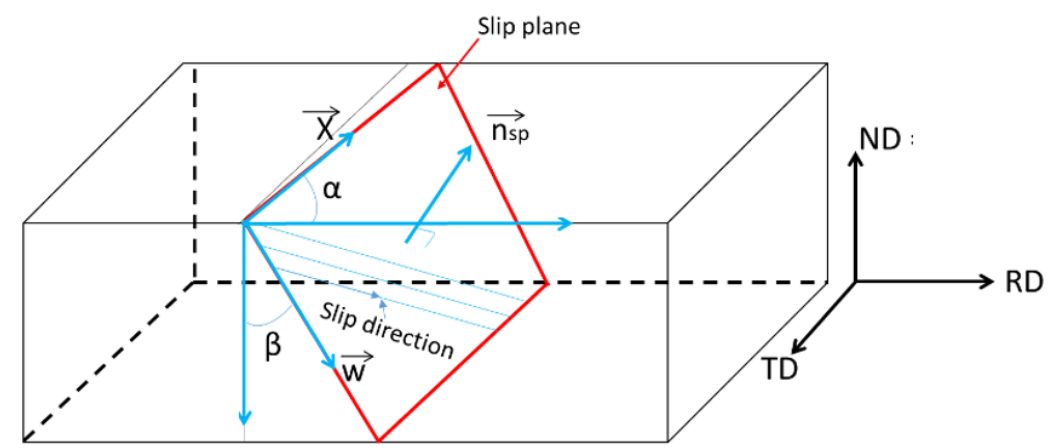

Fig. 1

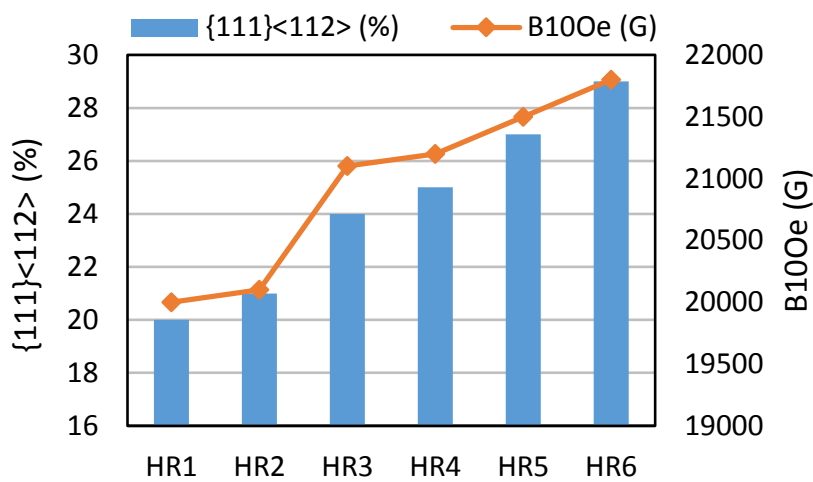

Fig. 2

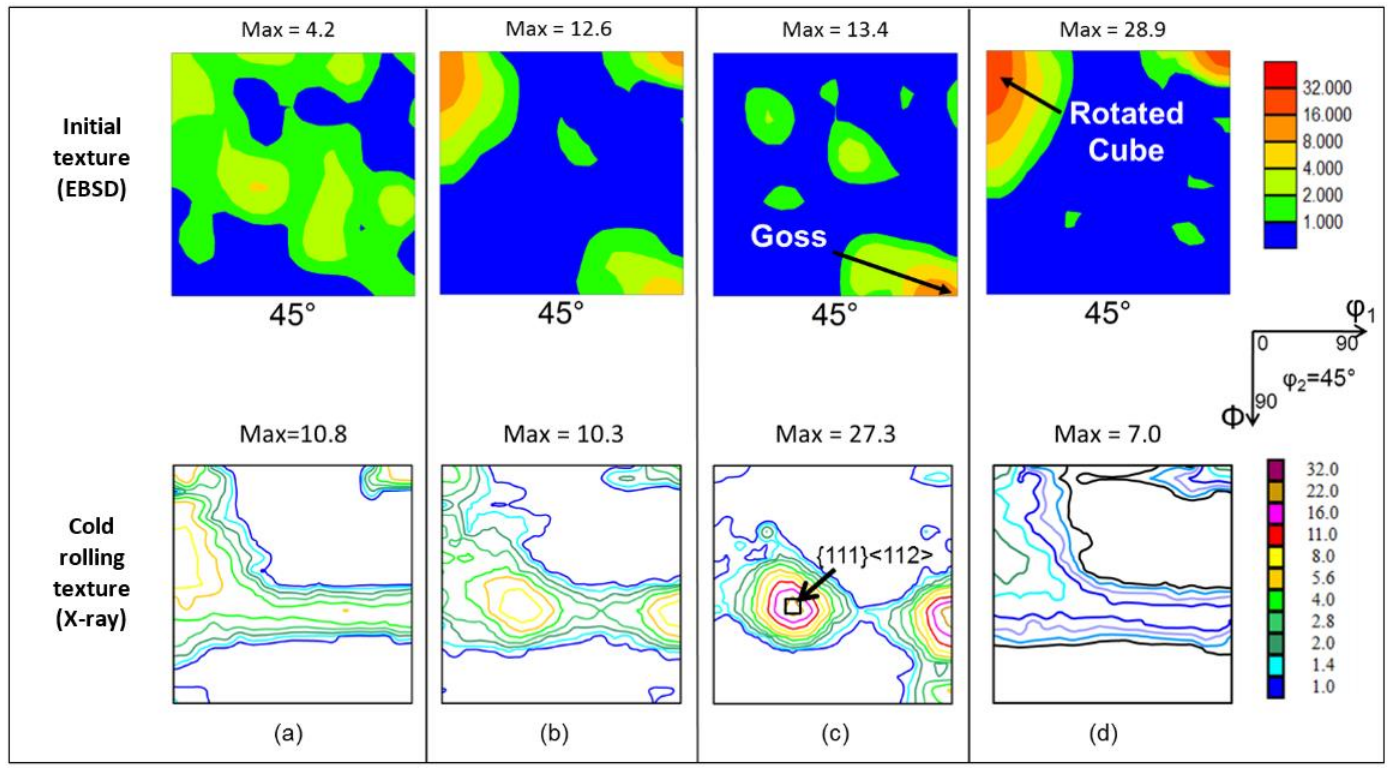

Fig. 3 


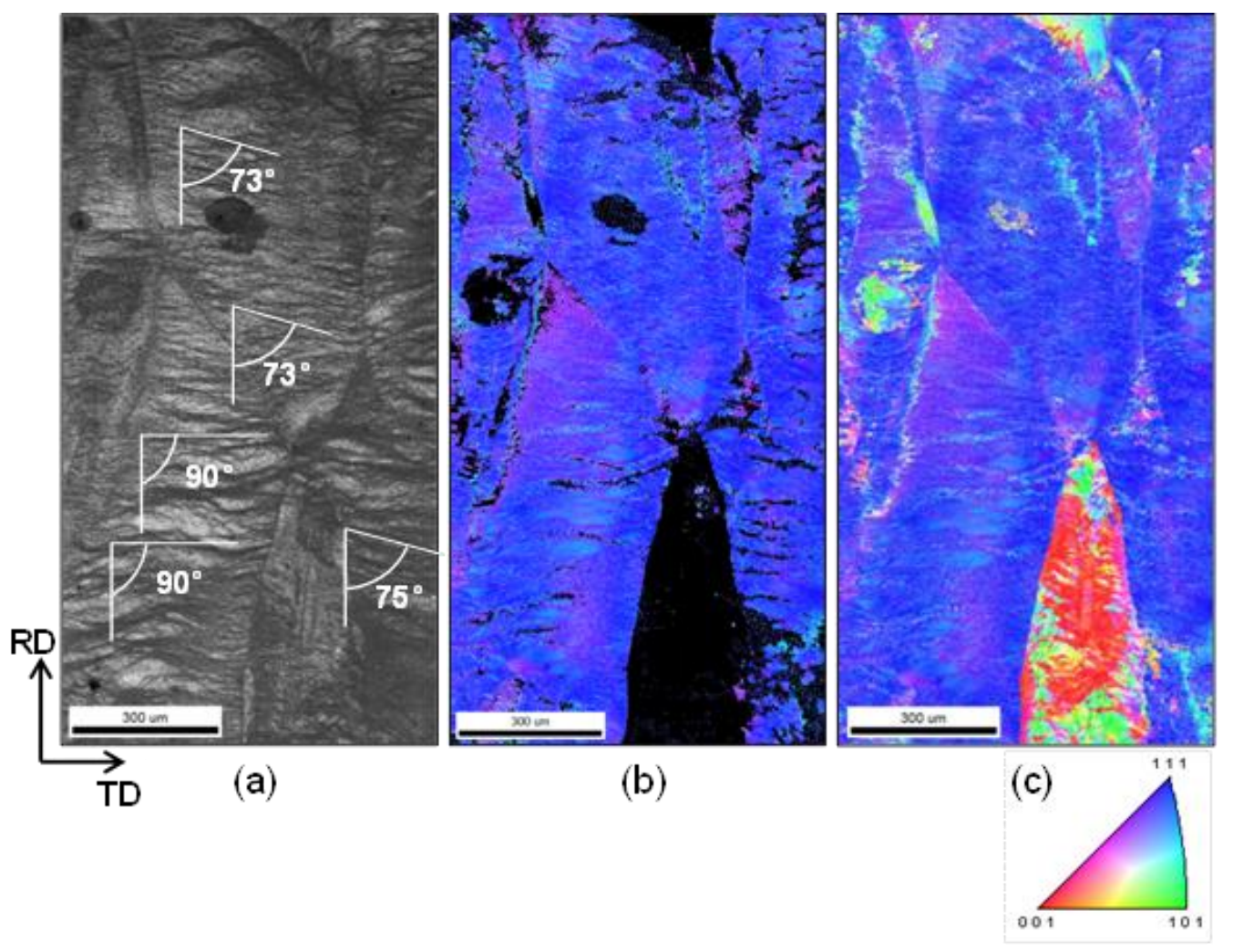

Fig. 4 


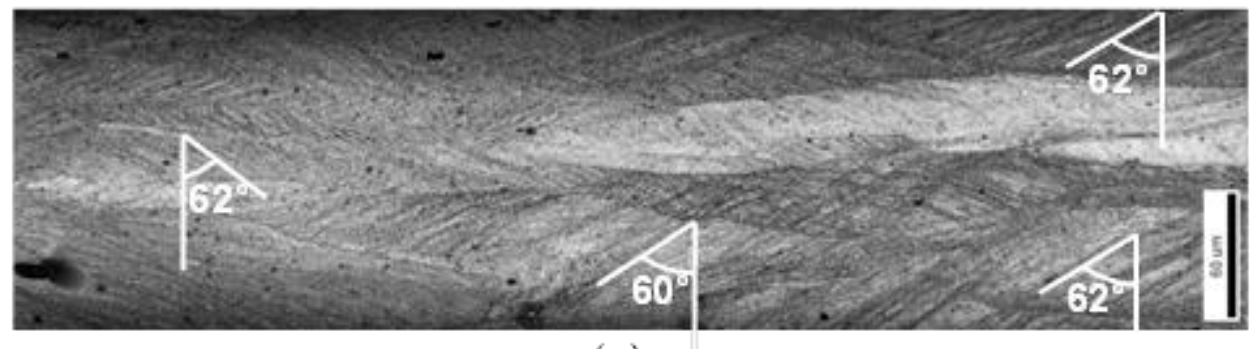

(a)

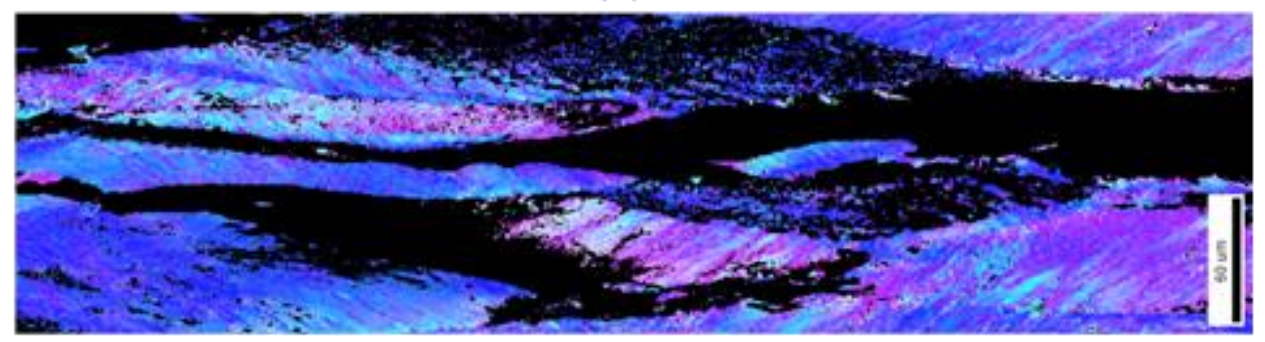

(b)

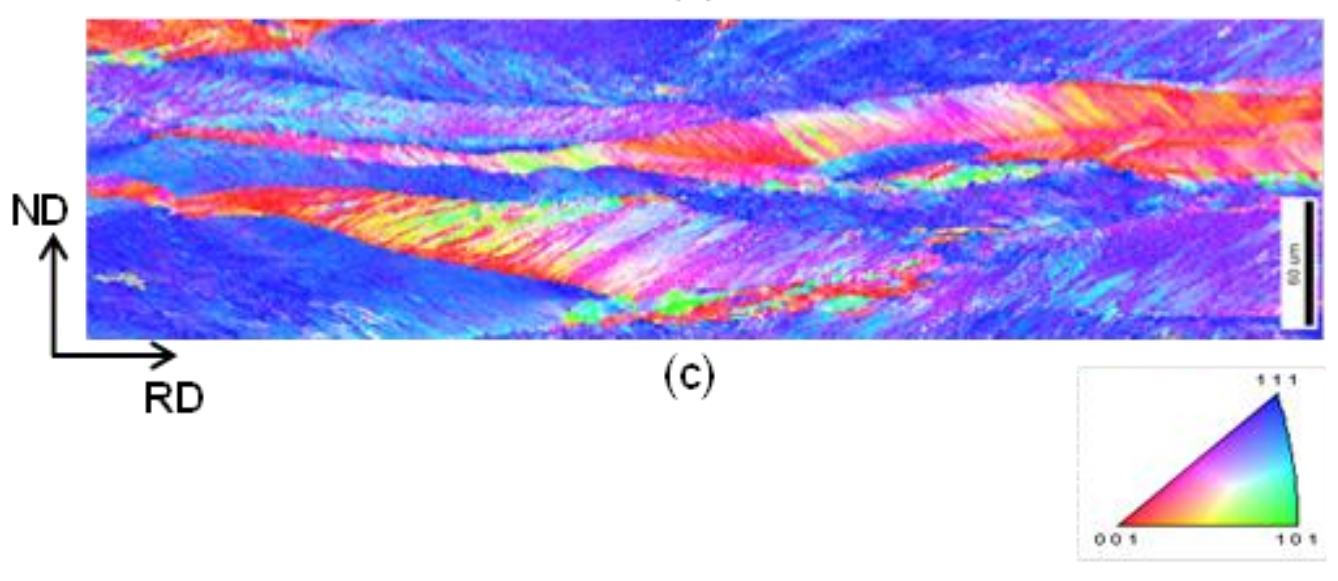

Fig. 5

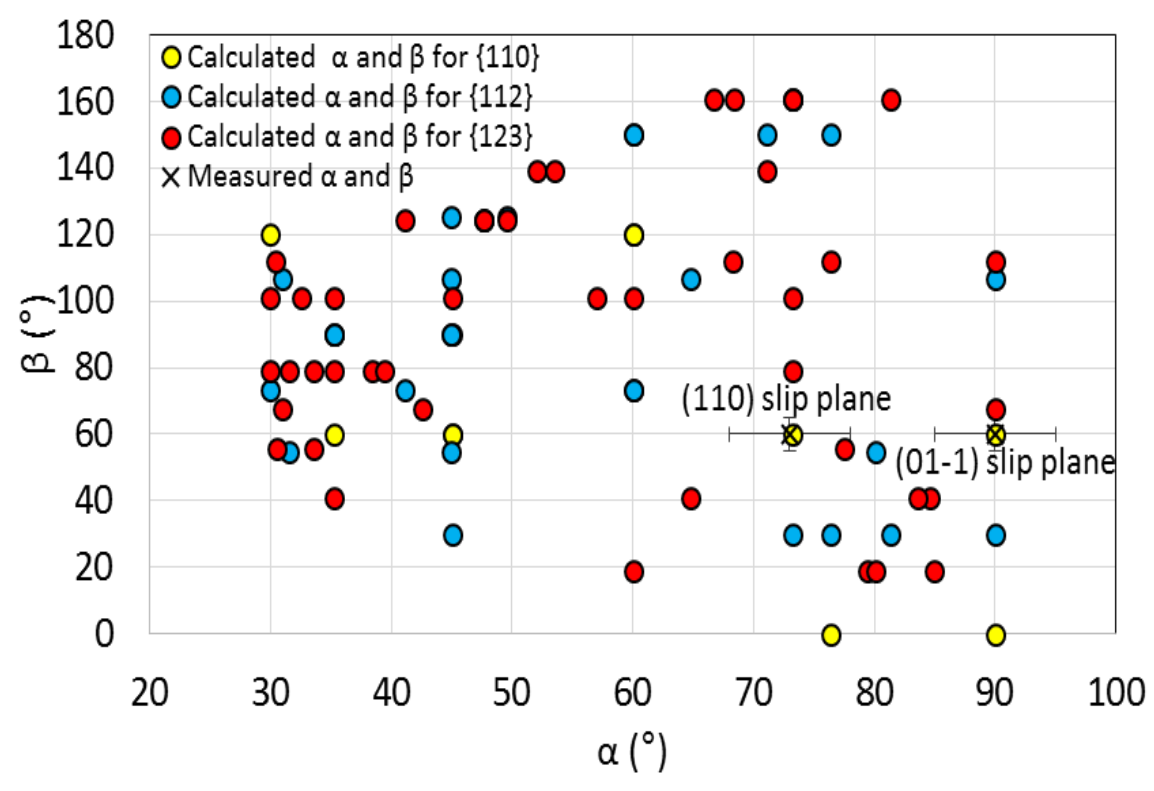

Fig. 6 


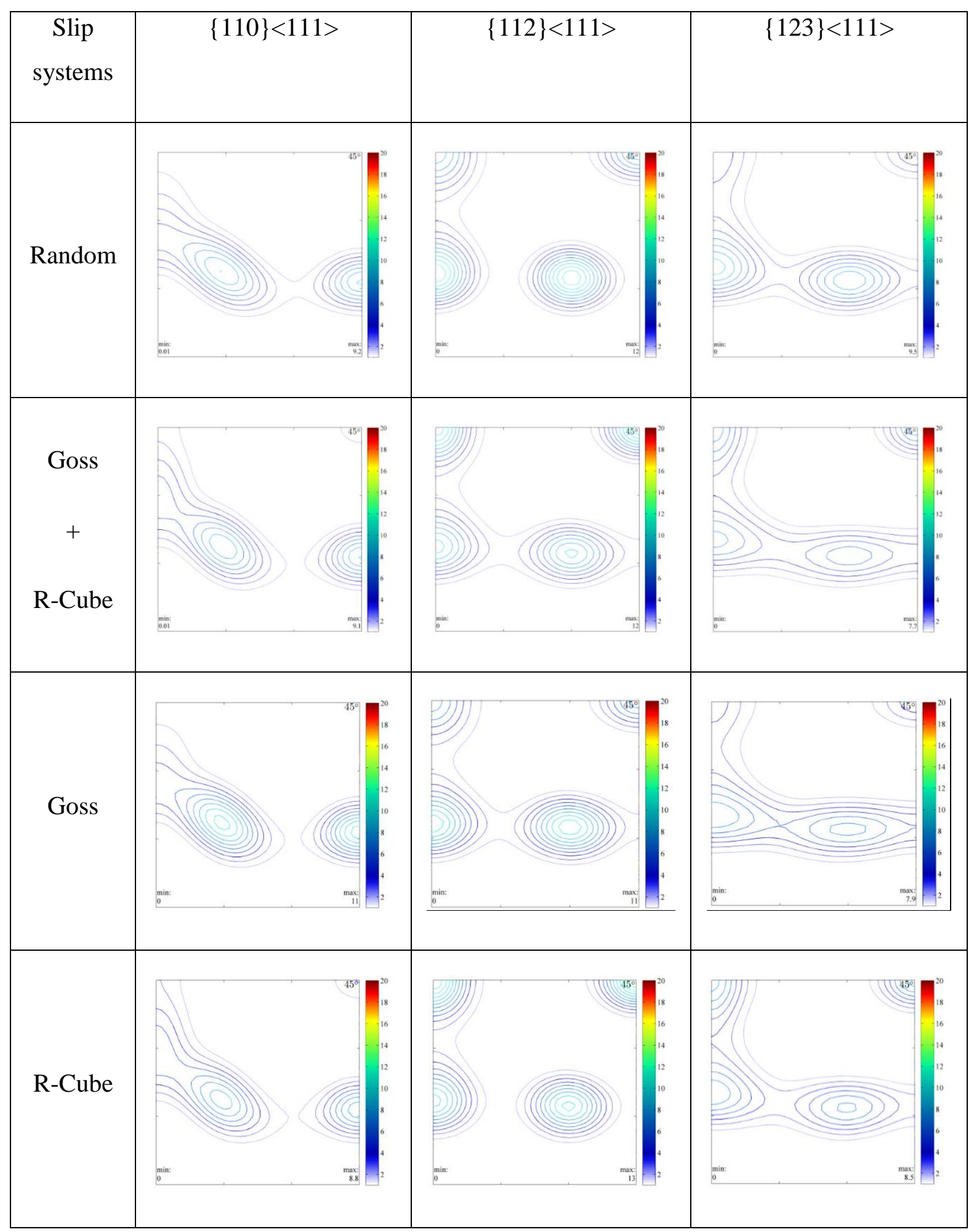

Fig. 7 


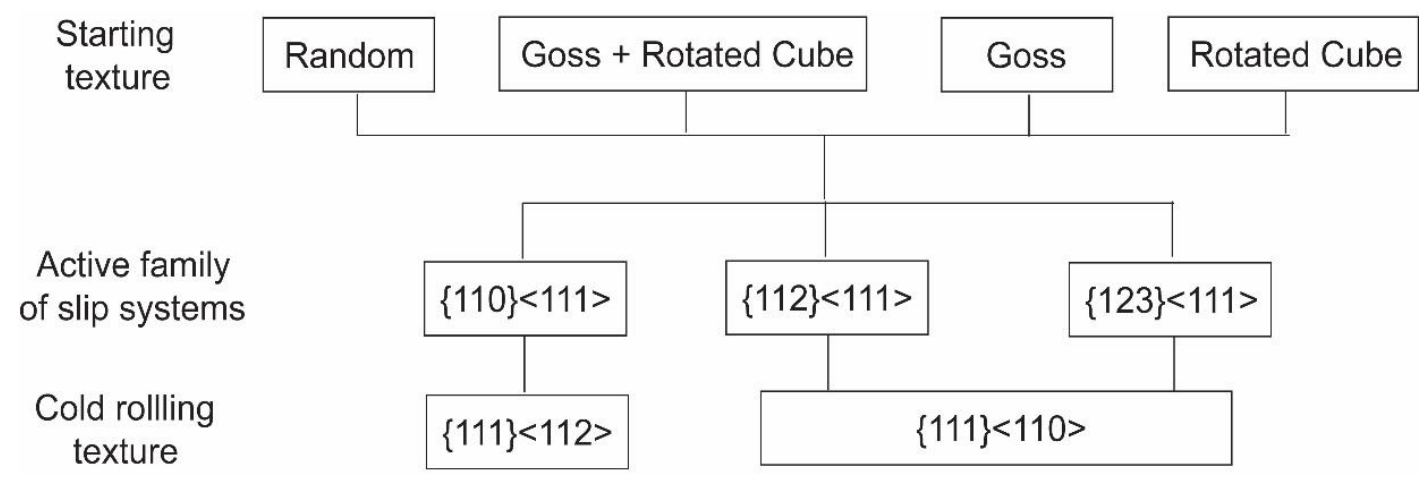

Fig. 8

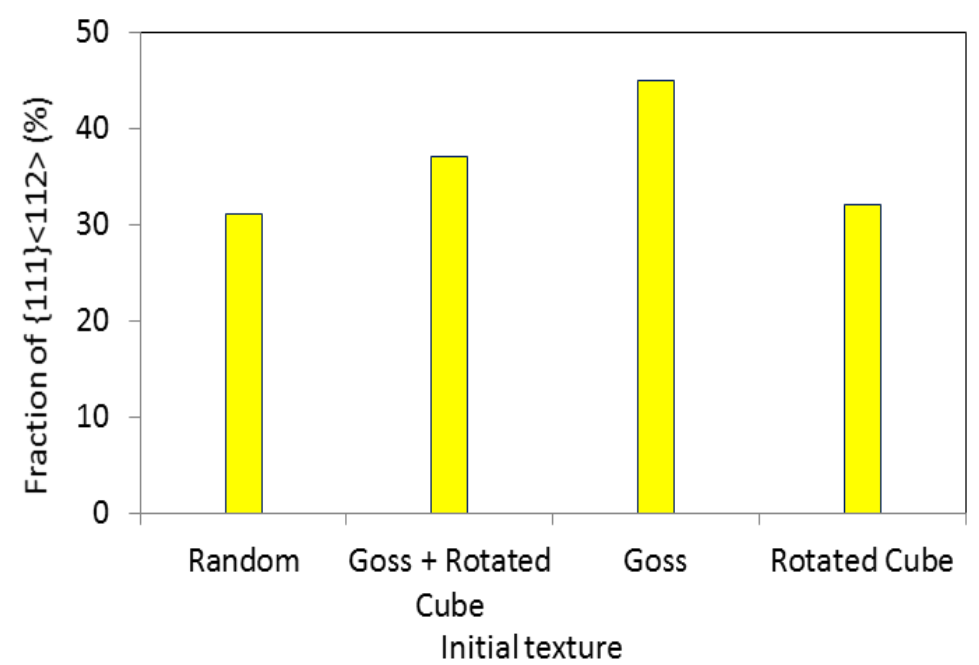

Fig. 9

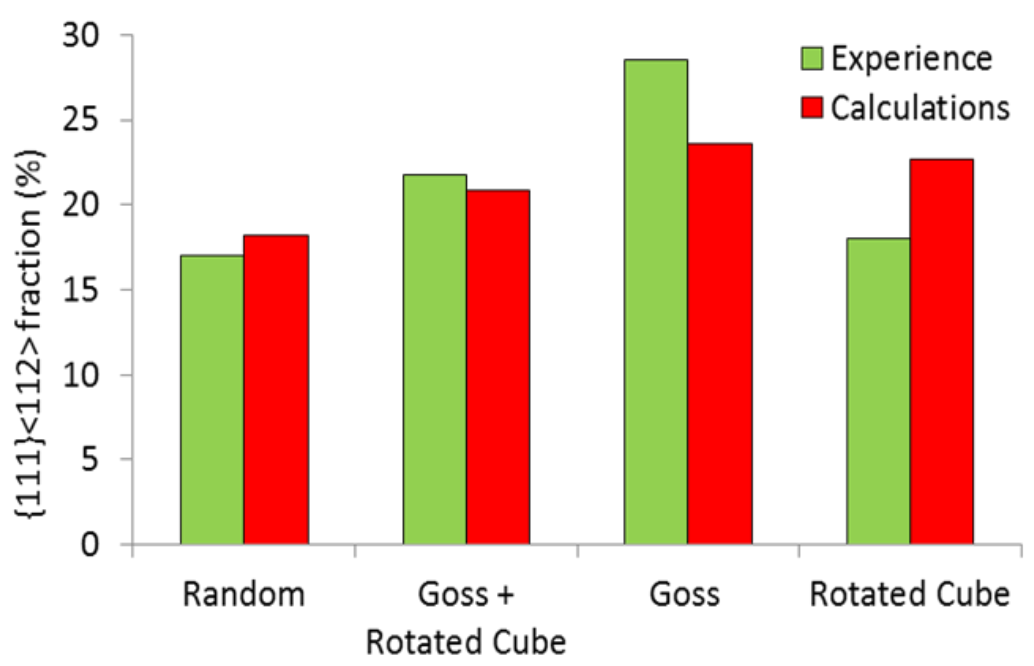

Fig. 10 
(0 111$)$

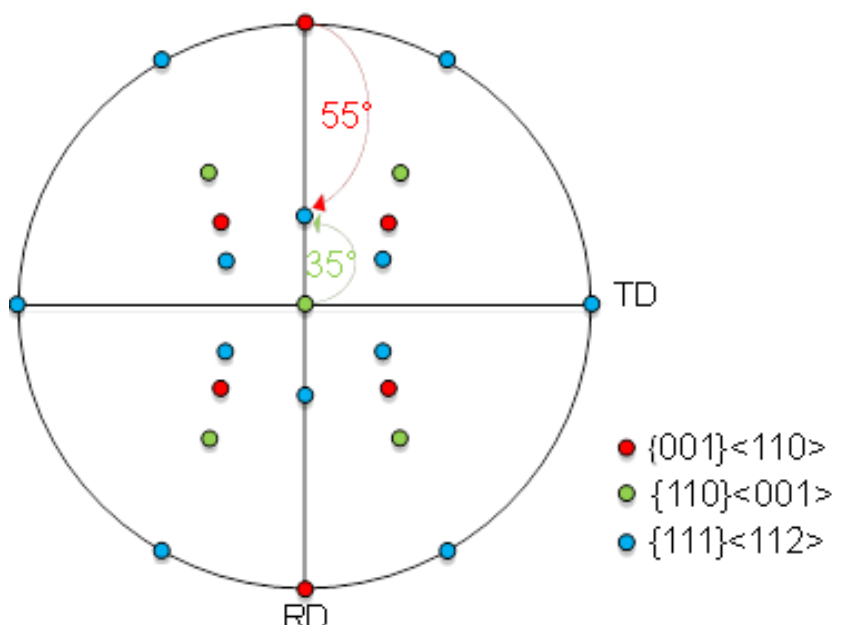

Fig. 11 